\begin{tabular}{|c|c|}
\hline Title & A nalysis of contribution to SPM by organic matters using high-performance liquid chromatography (HPLC) \\
\hline Author(s) & $\begin{array}{l}\text { Moriyoshi, A kihiro; Takano, Shin'ei; Ono, Makoto; Ogasawara, Masa'aki; Tabata, Masay oshi; Miyamoto, Noboru; } \\
\text { Ohta, Sachio }\end{array}$ \\
\hline Citation & SA E technical paper series, 2002-01-0653, 1-6 \\
\hline Issue Date & 2002 \\
\hline Doc URL & http:/hdl.handle.net/2115/42824 \\
\hline Rights & $\begin{array}{l}\text { "SA E Paper 2002-01-0653 (c) } 2002 \text { SA E International. This paper is posted on this website with permission from SA E } \\
\text { International. A s a user of this website, you are permitted to view this paper on-line, and print one copy of this paper at } \\
\text { no cost for your use only. This paper may not be copied, distributed or forwarded to others for any use without } \\
\text { permission from SA E. }\end{array}$ \\
\hline Type & article \\
\hline File Information & moriyoshi_SA E2002-01-0653.pdf \\
\hline
\end{tabular}

Instructions for use 


\section{Analysis of Contribution to SPM by Organic Matters Using High-Performance Liquid Chromatography (HPLC)}

Akihiro Moriyoshi, Shin'ei Takano and Makoto Ono

Department of Civil Engineering, Faculty of Engineering, Hokkaido Univ.

Masa'aki Ogasawara and Masayoshi Tabata Department of Chemical Engineering, Faculty of Engineering, Hokkaido Univ.

Noboru Miyamoto Department of Mechanical Engineering, Faculty of Engineering, Hokkaido Univ.

Sachio Ohta Department of Sanitary Engineering, Faculty of Engineering, Hokkaido Univ.

Reprinted From: Environmental Issues for the Automotive Industry

(SP-1672) 
The appearance of this ISSN code at the bottom of this page indicates SAE's consent that copies of the paper may be made for personal or internal use of specific clients. This consent is given on the condition, however, that the copier pay a per article copy fee through the Copyright Clearance Center, Inc. Operations Center, 222 Rosewood Drive, Danvers, MA 01923 for copying beyond that permitted by Sections 107 or 108 of the U.S. Copyright Law. This consent does not extend to other kinds of copying such as copying for general distribution, for advertising or promotionak pumposes, for creating new collective works, or for resale.

Quantity reprint rates can be obtained from the Customer Sales and Satisfaction Department.

To request permission to reprint a technical paper or permission to use copyrighted SAE publications in other works, contact the SAE Publications Group.

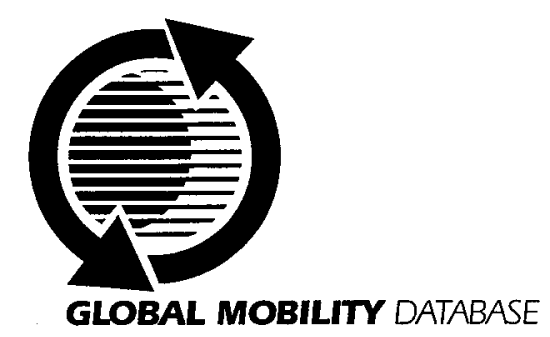

All SAE papers, standards, and selected books are abstracted and indexed in the Global Mobility Database

No part of this publication may be reproduced in any form, in an electronic retrieval system or otherwise, without the prior written permission of the publisher.

ISSN 0148-7191

Copyright 2002 Society of Automotive Engineers, Inc.

Positions and opinions advanced in this paper are those of the author(s) and not necessarily those of SAE. The author is solely responsible for the content of the paper. A process is available by which discussions will be printed with the paper if it is pu blished in SAE Transactions. For permission to publish this paper in full or in part, contact the SAE Publications Group.

Persons wishing to submit papers to be considered for presentation or publication through SAE should send the manuscript or a 300 word abstract of a proposed manuscript to: Secretary, Engineering Meetings Board, SAE.

\section{Printed in USA}




\title{
Analysis of Contribution to SPM by Organic Matters Using High-Performance Liquid Chromatography (HPLC)
}

\author{
Akihiro Moriyoshi, Shin'ei Takano and Makoto Ono \\ Department of Civil Engineering, Faculty of Engineering, Hokkaido Univ. \\ Masa'aki Ogasawara and Masayoshi Tabata \\ Department of Chemical Engineering, Faculty of Engineering, Hokkaido Univ. \\ Noboru Miyamoto \\ Department of Mechanical Engineering, Faculty of Engineering, Hokkaido Univ. \\ Sachio Ohta \\ Department of Sanitary Engineering, Faculty of Engineering, Hokkaido Univ.
}

Copyright $(\mathcal{C} 2002$ Society of Automotive Engineers, Inc.

\begin{abstract}
Most countries consider it is harmful for humans to inhale SPM of fine organic particles and elemental carbon less than $2.5 \mu$ in diameter ${ }^{1.2}$. It is generally believed that organic matters in SPM are mainly composed of diesel exhaust particulate and soot from residential chimneys or industrial smokestacks ${ }^{3.47}$. To determine the contribution ratios of several organic substances to SPM, we characterized SPM, diesel exhaust particulate (DEP), powdered summer radial tire, and bitumen, using high performance liquid chromatography, field desorption mass spectrometry and linear theory.
\end{abstract}

\section{INTRODUCTION}

Most countries consider suspended particulate matter (SPM) to be a major concern not only regarding the health of humans but also regarding impact on the natural environment ${ }^{5}$. SPM containing fine organic particles and elemental carbon less than $2.5 \mu$ in diameter is considered very harmful when inhaled by humans ${ }^{6}$. It is generally believed that the organic matters in SPM are mainly composed of diesel exhaust particulate (DEP) and soot from residential chimneys and industrial smokestacks. Many researchers have pursued the sources of organic matters in SPM using various methods, most often the chemical mass balance (CMB) method ${ }^{7.8)}$. However, the contribution ratio of those matters to SPM has not been found exactly, because these materials include with many types of complex organic matters ${ }^{9}$.
We tried to determine the contribution ratio of organic matters to SPM using the HPLC method and linear model. This method was found to be very effective in obtaining contribution ratio to SPM for diesel exhaust particulate, bitumen and summer radial tire.

\section{MATERIALS}

We collected SPM samples using a high-volume sampler (HVC-1000N: Shibata Scientific Technology, Palflex 2500QAT-UP, quart fiber filter, $23.5 \times 17.5 \mathrm{~cm}, 1000 \mathrm{l} / \mathrm{min} \times 4$ days, July $1-4,2000$ ) in Sapporo, at the top of the six-story building that houses our department. (Sapporo is a city in Northem Japan.) DEP samples were collected with air filter using dilution tunnel of Japan Automobile Research Institute in Tsukuba (Horiba, DLT-24150W). We collected bitumen (straight bitumen of penetration grade 80/100) used in Sapporo and abraded tire (summer radial tire). We prepared samples (SPM, DEP, bitumen, summer radial) for high-performance liquid chromatography (HPLC), as follows ${ }^{10}$.

We weighed a glass beaker containing the sample $(0.6 \mathrm{~g})$. The sample was dissolved in a benzene-methanol solution (1:1 by volume) using an ultrasonic vibration machine for 10 minutes, covered and cured for 1 day. The solution was absorbed and filtered with filter paper (mesh: No3). We reweighed the filter paper and glass beaker. The solution in the filter paper was evaporated by evaporator. After evaporation, it was dissolved with normal hexane $(20 \mathrm{ml})$, covered and cured for 1 day. We repeated the process from filtering to evaporation. Then, the filtrate was dissolved in a small amount of normal hexane and stored in a small glass beaker. 


\section{TEST METHOD}

The samples of SPM, bitumen, summer radial and DEP stored in small glass beakers were subjected to HPLC. They are classified according to four components: saturated hydrocarbon (paraffin component, FRP), aromatic hydrocarbon with 1 ring (FRM), aromatic hydrocarbon with 2 rings (FRD), and aromatic hydrocarbon with 3 or more rings (PP). They were stored in small glass beakers, each of whose weight was measured. Then, the solution was evaporated using nitrogen gas. Thereafter, FRP samples were performed using Field Disorption Mass Spectroscopy
(FD-MASS, JEOL JMS-SX102A, Inlet: direct, Normal lon: MF-Linear, RT: $2.27 \mathrm{~min} ., \mathrm{BP}: \mathrm{m} / \mathrm{z} 57.0000$ ) and the molecular weight distribution (200-1500) was measured.

\section{TEST RESULTS}

Figures 1, 2, 3 and 4 show FD-MASS spectra for SPM, DEP, bitumen and summer radial. The peaks of molecular weight for those samples were $532,504,616$ and 434 , respectively.

The spectrum of SPM was similar to that of DEP and different from that of summer radial.

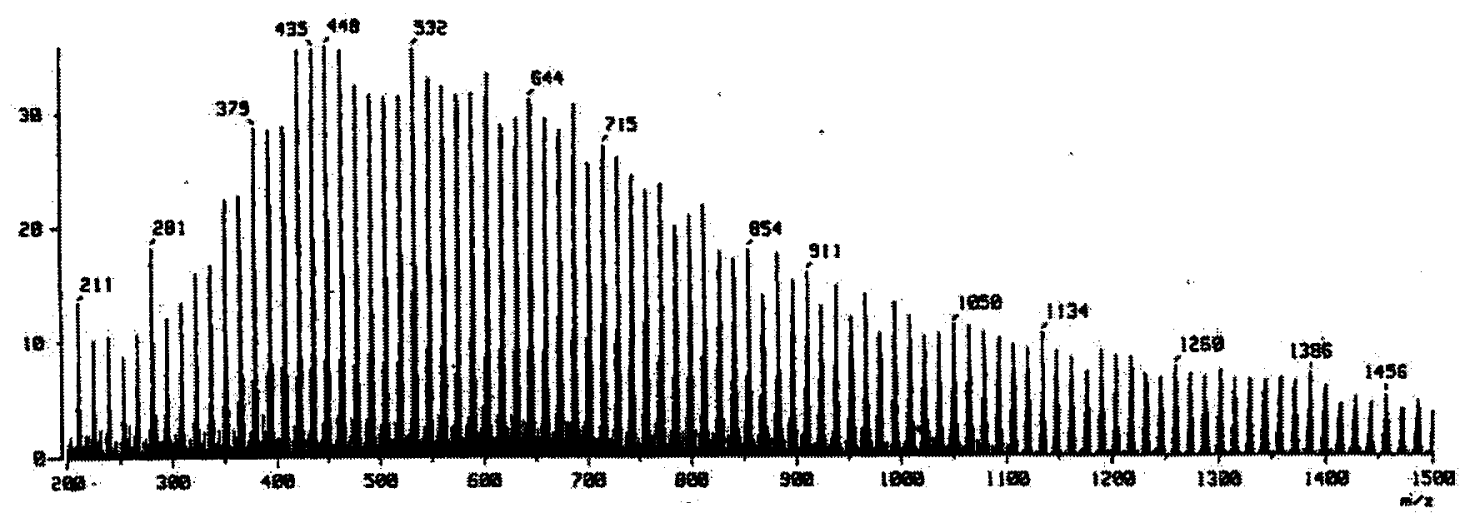

Fig.1 SPM

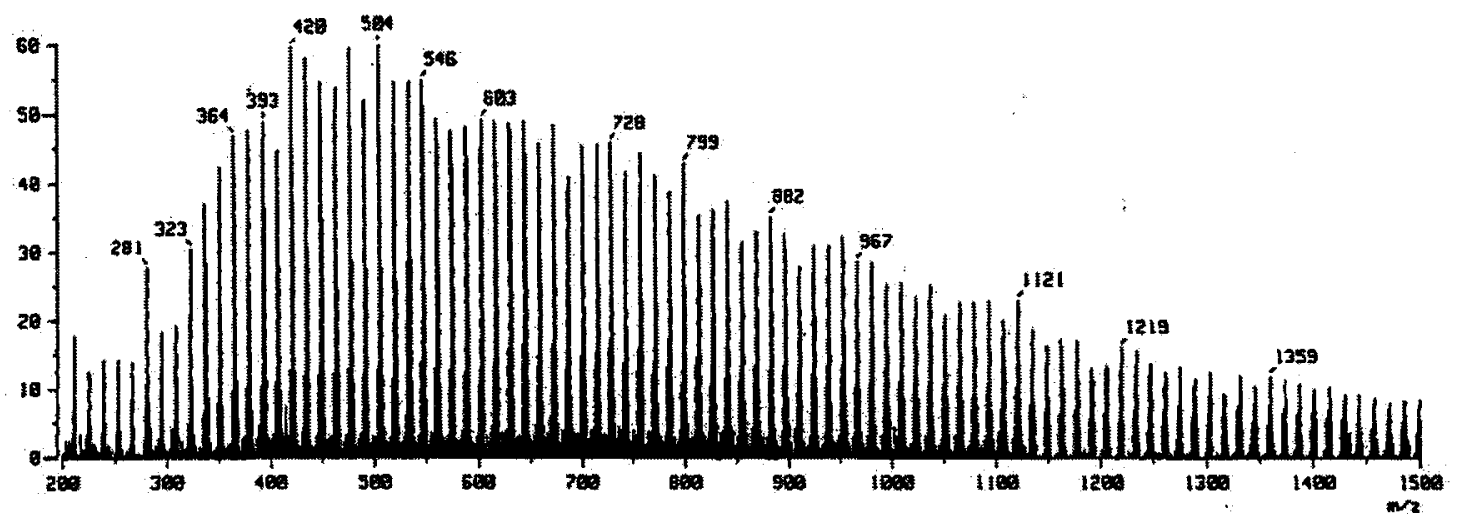

Fig.2 DEP

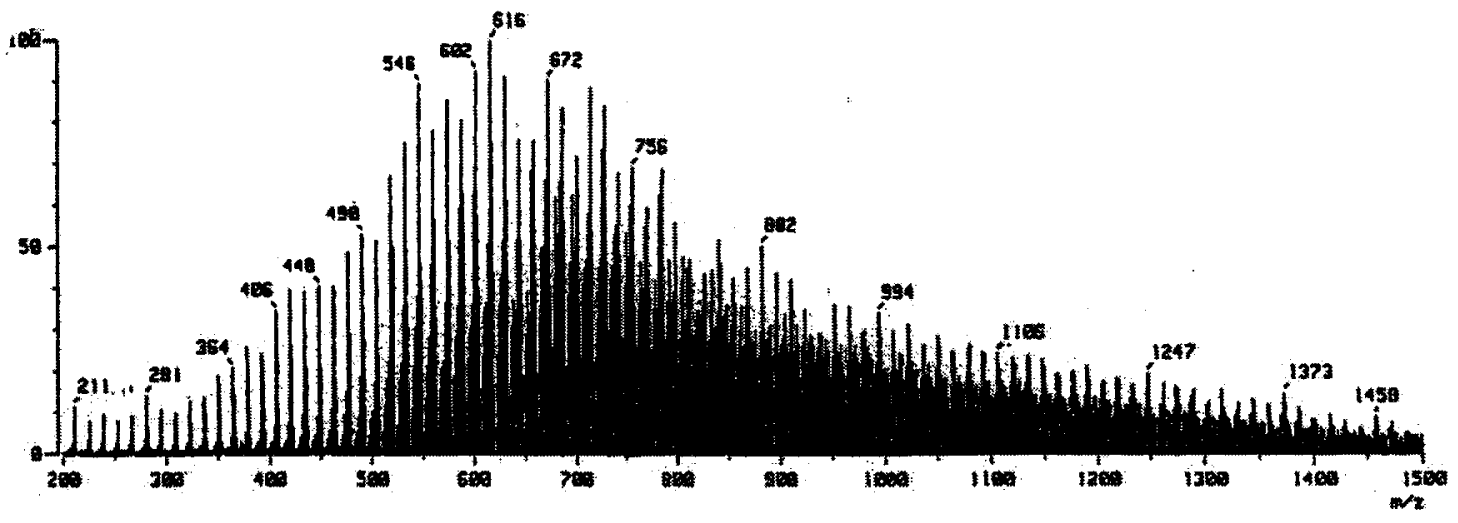

Fig.3 Bitumen 


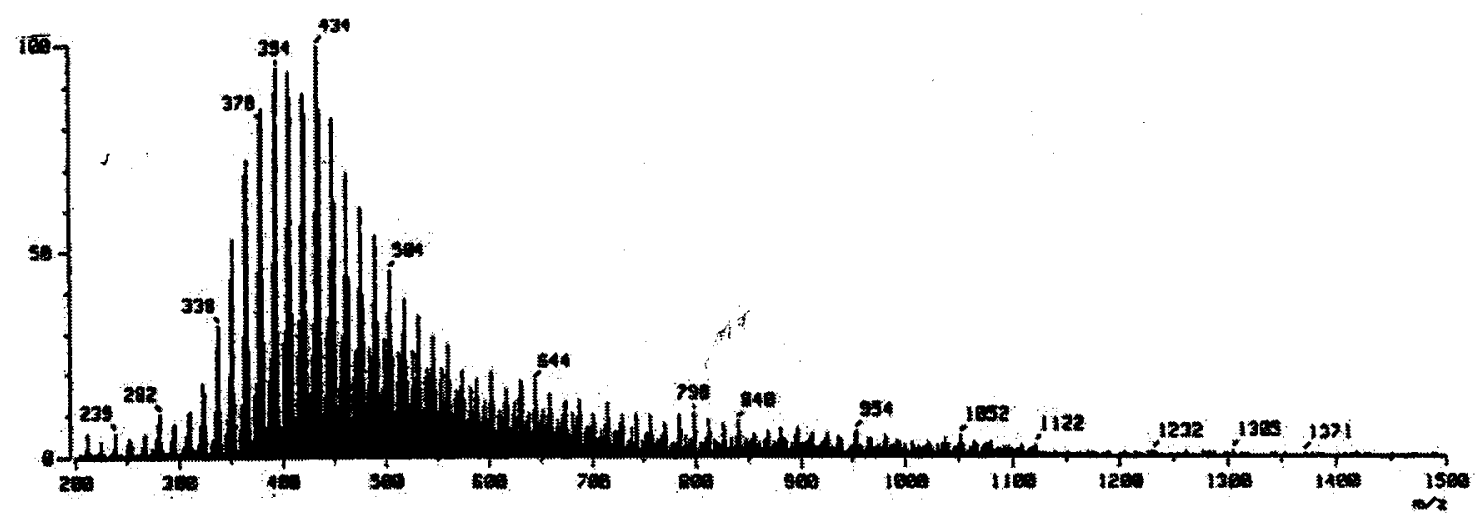

Fig.4 Radial Summer Tire

\section{ANALYSIS RESULTS}

We used linear theory to obtain correlation factors of SPM for those spectra, for every molecular weight from 200 to 900. Table 1 shows that the correlation factors of DEP (D) are almost as large as those of bitumen (B) for every molecular range and that they equal or exceed 0.9 for every molecular weight range. However, correlation factors averaged for both DEP and bitumen exceed those only for DEP in the distribution range of 200-600, considering with peak molecular values of each sample. In general, their correlation factors are lower for the molecular weights exceeding 600 . It is thought that the contribution ratio to SPM for DEP (D) and bitumen (B) is not always 1:1. We concluded that the contribution ratio to SPM was affected not only by DEP but also by bitumen.

\begin{tabular}{|l|l|l|l|l|l|l|l|}
\hline Mol. wt. & DEP & Bitumen & $(\mathrm{D}+\mathrm{B}) / 2$ & Mol. wt & DEP & Bitumen & $(\mathrm{D}+\mathrm{B}) / 2$ \\
\hline $200-300$ & 0.9720 & 0.9702 & 0.9783 & $400-600$ & 0.8868 & 0.8086 & 0.9138 \\
\hline $200-400$ & 0.9777 & 0.9783 & 0.9827 & $400-700$ & 0.9152 & 0.7134 & 0.8791 \\
\hline $200-500$ & 0.9040 & 0.9482 & 0.9567 & $400-800$ & 0.9269 & 0.6645 & 0.8576 \\
\hline $200-600$ & 0.9133 & 0.8071 & 0.9241 & $400-900$ & 0.9276 & 0.6483 & 0.8507 \\
\hline $200-700$ & 0.9297 & 0.7172 & 0.8853 & $500-600$ & 0.9268 & 0.8478 & 0.9360 \\
\hline $200-800$ & 0.9373 & 0.6669 & 0.8581 & $500-700$ & 0.9549 & 0.7735 & 0.9080 \\
\hline $200-900$ & 0.9368 & 0.6421 & 0.8444 & $500-800$ & 0.9609 & 0.7277 & 0.8900 \\
\hline $300-400$ & 0.9832 & 0.9797 & 0.9864 & $500-900$ & 0.9571 & 0.7144 & 0.8845 \\
\hline $300-500$ & 0.8949 & 0.9466 & 0.9546 & $600-700$ & 0.9904 & 0.7543 & 0.8972 \\
\hline $300-600$ & 0.9067 & 0.7971 & 0.9215 & $600-800$ & 0.9838 & 0.7110 & 0.8865 \\
\hline $300-700$ & 0.9252 & 0.7019 & 0.8821 & $600-900$ & 0.9734 & 0.6961 & 0.8808 \\
\hline $300-800$ & 0.9338 & 0.6503 & 0.8559 & $700-800$ & 0.9827 & 0.6656 & 0.8781 \\
\hline $300-900$ & 0.9340 & 0.6281 & 0.8448 & $700-900$ & 0.9717 & 0.6380 & 0.8653 \\
\hline $400-500$ & 0.8508 & 0.9539 & 0.9392 & $800-900$ & 0.9629 & 0.5556 & 0.8357 \\
\hline
\end{tabular}

Table 1 Correlation factors for DEP (D) and bitumen (B), and the average of both samples

Table 2 shows correlation factors of SPM for different contribution ratios of DEP (D) and bitumen (B). This analysis revealed that large correlation factors $(>0.9)$ were obtained for the ratio of (5 DEP +5 Bitumen) / 10 or (6 DEP +4 Bitumen) / 10. These correlation factors were: $1: 1$ or $3: 2$
(DEP:bitumen) for the molecular weight range of 200 to 600. Table 2 shows that a contribution ratio to SPM of more than 0.93 was obtained for DEP and bitumen at 1:1 or $3: 2$ for molecular weight range of 200-600. 


\begin{tabular}{|l|l|l|l|l|l|l|}
\hline Mol. wt. & $\begin{array}{l}(1 \mathrm{D}+9 \mathrm{~B}) \\
/ 10\end{array}$ & $\begin{array}{l}(2 \mathrm{D}+8 \mathrm{~B}) \\
/ 10\end{array}$ & $\begin{array}{l}(3 \mathrm{D}+7 \mathrm{~B}) \\
/ 10\end{array}$ & $\begin{array}{l}(4 \mathrm{D}+6 \mathrm{~B}) \\
110\end{array}$ & $\begin{array}{l}(5 \mathrm{D}+5 \mathrm{~B}) \\
/ 10\end{array}$ & $\begin{array}{l}(6 \mathrm{D}+4 \mathrm{~B}) \\
/ 10\end{array}$ \\
\hline $200-300$ & 0.9747 & 0.9772 & 0.9784 & 0.9787 & 0.9783 & 0.9775 \\
\hline $200-400$ & 0.9817 & 0.9833 & 0.9836 & 0.9834 & 0.9827 & 0.9819 \\
\hline $200-500$ & 0.9602 & 0.9659 & 0.9665 & 0.9631 & 0.9567 & 0.9481 \\
\hline $200-600$ & 0.8375 & 0.8653 & 0.8895 & 0.9094 & 0.9241 & 0.9331 \\
\hline $300-400$ & 0.9836 & 0.9856 & 0.9864 & 0.9866 & 0.9864 & 0.9859 \\
\hline $300-500$ & 0.9596 & 0.9657 & 0.9661 & 0.9620 & 0.9546 & 0.9448 \\
\hline $300-600$ & 0.8295 & 0.8592 & 0.8851 & 0.9062 & 0.9215 & 0.9307 \\
\hline $400-500$ & 0.9621 & 0.9639 & 0.9601 & 0.9515 & 0.9392 & 0.9241 \\
\hline $400-600$ & 0.8362 & 0.8616 & 0.8836 & 0.9013 & 0.9138 & 0.9204 \\
\hline $500-600$ & 0.8809 & 0.8990 & 0.9154 & 0.9296 & 0.9360 & 0.9480 \\
\hline \hline Mol.wt & $(7 \mathrm{D}+3 \mathrm{~B})$ & $(8 \mathrm{D}+2 \mathrm{~B})$ & $\begin{array}{l}(9 \mathrm{D}+1 \mathrm{~B}) \\
/ 10\end{array}$ & $\mathrm{DEP}$ & $\mathrm{Bitumen}$ & \\
\hline $200-300$ & 0.9764 & 0.9751 & 0.9736 & 0.9721 & 0.9702 & \\
\hline $200-400$ & 0.9809 & 0.9798 & 0.9787 & 0.9777 & 0.9783 & \\
\hline $200-500$ & 0.9381 & 0.9272 & 0.9157 & 0.9041 & 0.9482 & \\
\hline $200-600$ & 0.9362 & 0.9337 & 0.9258 & 0.9133 & 0.8071 & \\
\hline $300-400$ & 0.9853 & 0.9846 & 0.9839 & 0.9832 & 0.9797 & \\
\hline $300-500$ & 0.9334 & 0.9210 & 0.9080 & 0.8949 & 0.9466 & \\
\hline $300-600$ & 0.9334 & 0.9299 & 0.9208 & 0.9067 & 0.7971 & \\
\hline $400-500$ & 0.9071 & 0.8888 & 0.8699 & 0.8507 & 0.9539 & \\
\hline $400-600$ & 0.9209 & 0.9151 & 0.9036 & 0.8869 & 0.8086 & \\
\hline $500-600$ & 0.9508 & 0.9484 & 0.9405 & 0.9268 & 0.8478 & \\
\hline
\end{tabular}

Table 2 Correlation factors for various ratios of DEP (D) to bitumen (B)

Then, we calculated correlation factors of SPM for DEP, bitumen and summer radial $(T)$ using both ratios $(D: B=1: 1$ and 3:2). Table 3 shows that summer radial does not affect the correlation factor for ratios lower than $4: 4: 1$ (D:B:T), when the ratio of DEP to bitumen is kept at 1:1. Larger correlation factors of SPM were obtained for 4:4:1 (D:B:T), when a ratio of $1.1(D: B)$ was kept.

\begin{tabular}{|l|l|l|l|l|l|l|}
\hline Mol. wt & Tire & & $\begin{array}{l}(\mathrm{D}+\mathrm{B}+\mathrm{T}) \\
/ 3\end{array}$ & $\begin{array}{l}(2 \mathrm{D}+2 \mathrm{~B}+\mathrm{T}) / \\
5\end{array}$ & $\begin{array}{l}(3 \mathrm{D}+3 \mathrm{~B}+\mathrm{T}) / \\
7\end{array}$ & $\begin{array}{l}(4 \mathrm{D}+4 \mathrm{~B}+\mathrm{T}) \\
/ 9\end{array}$ \\
\hline $200-300$ & 0.7723 & & 0.9568 & 0.9784 & 0.9791 & 0.9792 \\
\hline $200-400$ & 0.7496 & & 0.8707 & 0.9534 & 0.9659 & 0.9717 \\
\hline $200-500$ & 0.7568 & & 0.8335 & 0.9397 & 0.9484 & 0.9521 \\
\hline $200-600$ & 0.6579 & & 0.8559 & 0.9323 & 0.9345 & 0.9342 \\
\hline $300-400$ & 0.7848 & & 0.8789 & 0.9653 & 0.9756 & 0.9802 \\
\hline $300-500$ & 0.7667 & & 0.8318 & 0.9441 & 0.9511 & 0.9538 \\
\hline $300-600$ & 0.6468 & & 0.8599 & 0.9372 & 0.9375 & 0.9360 \\
\hline $400-500$ & 0.7697 & & 0.8119 & 0.9379 & 0.9417 & 0.9428 \\
\hline $400-600$ & 0.6065 & & 0.8629 & 0.9357 & 0.9335 & 0.9307 \\
\hline $500-600$ & 0.5681 & & 0.9289 & 0.9401 & 0.9410 & 0.9413 \\
\hline \hline Mol.wt & $(5 \mathrm{D}+5 \mathrm{~B}+\mathrm{T}) /$ & $(6 \mathrm{D}+6 \mathrm{~B}+\mathrm{T}) /$ & $(7 \mathrm{D}+7 \mathrm{~B}+\mathrm{T}) /$ & $(8 \mathrm{D}+8 \mathrm{~B}+\mathrm{T}) /$ & $(9 \mathrm{D}+9 \mathrm{~B}+\mathrm{T}) /$ & $(10 \mathrm{D}+10 \mathrm{~B}+\mathrm{T})$ \\
& 11 & 13 & 15 & 17 & 19 & $/ 21$ \\
\hline $200-300$ & 0.9792 & 0.9791 & 0.9791 & 0.9790 & 0.9790 & 0.9789 \\
\hline $200-400$ & 0.9749 & 0.9768 & 0.9781 & 0.9789 & 0.9796 & 0.9801 \\
\hline $200-500$ & 0.9539 & 0.9550 & 0.9556 & 0.9560 & 0.9563 & 0.9565 \\
\hline $200-600$ & 0.9333 & 0.9325 & 0.9317 & 0.9311 & 0.9305 & 0.9300 \\
\hline $300-400$ & 0.9825 & 0.9839 & 0.9847 & 0.9853 & 0.9856 & 0.9859 \\
\hline $300-500$ & 0.9550 & 0.9555 & 0.9558 & 0.9559 & 0.9560 & 0.9560 \\
\hline $300-600$ & 0.9344 & 0.9330 & 0.9318 & 0.9309 & 0.9300 & 0.9294 \\
\hline $400-500$ & 0.9430 & 0.9430 & 0.9427 & 0.9425 & 0.9424 & 0.9422 \\
\hline $400-600$ & 0.9284 & 0.9266 & 0.9252 & 0.9240 & 0.9231 & 0.9223 \\
\hline $500-600$ & 0.9413 & 0.9413 & 0.9413 & 0.9412 & 0.9412 & 0.9412 \\
\hline
\end{tabular}

Table 3 Correlation factors of SPM when the ratio of DEP $(D)$ to bitumen $(B)$ is 1:1 
In contrast, Table 4 shows that larger correlation ratio was obtained for $(6: 4: 1) / 11$ or $(9: 6: 1) / 16$ (D:B:T), when the ratio was kept at $3: 2(D: B)$. Therefore, summer radial $(T)$ also is shown to contribute to SPM, by the increase in correlation factors of SPM for both cases with addition of summer radial.

\begin{tabular}{|l|l|l|l|l|l|l|}
\hline Mol. $\mathrm{Wt}^{\mathrm{t}}$ & $\begin{array}{l}(3 \mathrm{D}+2 \mathrm{~B}+\mathrm{T}) \\
/ 6\end{array}$ & $\begin{array}{l}(6 \mathrm{D}+4 \mathrm{~B}+\mathrm{T}) \\
/ 11\end{array}$ & $\begin{array}{l}(9 \mathrm{D}+6 \mathrm{~B}+\mathrm{T}) / \\
16\end{array}$ & $\begin{array}{l}(12 \mathrm{D}+8 \mathrm{~B}+\mathrm{T}) \\
/ 21\end{array}$ & $\begin{array}{l}(15 \mathrm{D}+10 \mathrm{~B}+\mathrm{T}) \\
/ 26\end{array}$ & $\begin{array}{l}(18 \mathrm{D}+12 \mathrm{~B}+\mathrm{T}) \\
/ 31\end{array}$ \\
\hline $200-300$ & 0.9783 & 0.9784 & 0.9782 & 0.9781 & 0.9780 & 0.9779 \\
\hline $200-400$ & 0.9629 & 0.9753 & 0.9785 & 0.9798 & 0.9804 & 0.9808 \\
\hline $200-500$ & 0.9410 & 0.9478 & 0.9490 & 0.9492 & 0.9492 & 0.9492 \\
\hline $200-600$ & 0.9384 & 0.9397 & 0.9386 & 0.9376 & 0.9369 & 0.9364 \\
\hline $300-400$ & 0.9741 & 0.9834 & 0.9854 & 0.9860 & 0.9863 & 0.9864 \\
\hline $300-500$ & 0.9433 & 0.9476 & 0.9477 & 0.9474 & 0.9471 & 0.9469 \\
\hline $300-600$ & 0.9416 & 0.9404 & 0.9383 & 0.9369 & 0.9359 & 0.9351 \\
\hline $400-500$ & 0.9306 & 0.9307 & 0.9295 & 0.9285 & 0.9278 & 0.9273 \\
\hline $400-600$ & 0.9367 & 0.9325 & 0.9295 & 0.9276 & 0.9263 & 0.9255 \\
\hline $500-600$ & 0.9476 & 0.9484 & 0.9484 & 0.9484 & 0.9483 & 0.9483 \\
\hline
\end{tabular}

Table 4 Correlation factors of SPM when ratio of DEP (D) to bitumen (B) is 3:2

It was concluded that ratios of three materials having larger correlation factors (D:B:T) were best in $(4: 4: 1) / 9$ or $(6: 4: 1) / 11$ or $(9: 6: 1) / 16$ in shown in Table 3 and Table 4. Therefore, the largest correlation factor (D:B:T) for the molecular weight range of 200-600 in Table 5 (0.9397) was for (6D:4B:1T)/11. Contribution ratios (D:B:T) to SPM for these three materials were $54.5 \%: 36.4 \%: 9.1 \%$ for summer in Sapporo.

\begin{tabular}{|l|l|l|l|l|l|l|l|}
\hline Mol. wt & DEP & Bitumen & & Tire & $\begin{array}{l}(4 \mathrm{D}+4 \mathrm{~B}+\mathrm{T}) / \\
9\end{array}$ & $\begin{array}{l}(6 \mathrm{D}+4 \mathrm{~B}+\mathrm{T}) / \\
11\end{array}$ & $\begin{array}{l}(9 \mathrm{D}+6 \mathrm{~B}+\mathrm{T}) / \\
16\end{array}$ \\
\hline $200-300$ & 0.9721 & 0.9702 & & 0.7723 & 0.9792 & 0.9784 & 0.9782 \\
\hline $200-400$ & 0.9777 & 0.9783 & & 0.7496 & 0.9717 & 0.9753 & 0.9785 \\
\hline $200-500$ & 0.9041 & 0.9482 & & 0.7568 & 0.9521 & 0.9478 & 0.9490 \\
\hline $200-600$ & 0.9133 & 0.8071 & & 0.6579 & 0.9342 & 0.9397 & 0.9386 \\
\hline $300-400$ & 0.9832 & 0.9797 & & 0.7848 & 0.9802 & 0.9834 & 0.9854 \\
\hline $300-500$ & 0.8949 & 0.9466 & & 0.7667 & 0.9538 & 0.9476 & 0.9477 \\
\hline $300-600$ & 0.9067 & 0.7971 & & 0.6468 & 0.9360 & 0.9404 & 0.9383 \\
\hline $400-500$ & 0.8507 & 0.9539 & & 0.7697 & 0.9428 & 0.9307 & 0.9295 \\
\hline $400-600$ & 0.8869 & 0.8086 & & 0.6065 & 0.9307 & 0.9325 & 0.9295 \\
\hline $500-600$ & 0.926790 & 0.8478 & & 0.5681 & 0.9413 & 0.9484 & 0.9484 \\
\hline
\end{tabular}

Table 5 Correlation factors of SPM when ratio of DEP (D) to bitumen (B) is varied

\section{CONCLUSIONS}

These conclusions were obtained.

1. Organic matters in SPM include DEP, bitumen, and summer radial tire.

2. Correlation factors for those materials in SPM differ slightly at various molecular ranges, but they increase with addition of bitumen and summer radial tire.

3. Correlation factors of SPM for DEP (D) are almost as large as those of bitumen (B) for every molecular range: They are almost 0.9 or greater.

4. The FD MASS analysis method is very effective in determining the contribution ratio to SPM for DEP, bitumen and summer radial tire.
5. Contribution ratios $(D: B: T)$ of organic matters to SPM in Sapporo in summer for the molecular weight range of $200-600$ are $56 \%, 38 \%$ and 6 $\%$ for DEP, bitumen and summer radial, respectively.

\section{ACKNOWLEGEMENTS}

We would like to thank K. Teramachi and T. Nakajima for their technical contributions.

\section{REFERENCES}

1. U.S. Dhew, National Air Poll. Contr. Adminst. No.AP-49, 119(1969)

2. Gross, G.P., SAE Paper, 720210 (1972)

3. S.Ohta, N. Kaneyasu, Atmos. Environ. 24A (1990)

4. William R. Pierson and Wanda W. Brachaczek, Aerosol Science and Technology 2:1-40 (1983) 
5. Kaneyasu, N. Ohta, S., Murao, N. and Mizoguchi, I., J. Climate, 4 (1991)

6. John H. Seinfold, John willey \& Sons, Atmospheric Chemistry and, Physics of Air Pollution, pp68(1986)

7. Sheldon K. Friendlander, Smoke, Dust, and Haze, Oxford University Press,pp380-385(2000)

8. Philip K. Hopke, Receptor modeling for air quality management, Elsevier, pp3-8(1991)

9. R.C.Lao, R.S.Thomas, H. Oja and L. Dubois, Analytical Chemistry, Vol. 45, No. 6, 908-915(1973)

10. M. Ogasawara, Chemistry, Vol. 54 , No. $9,28-30$ (1999) (in Japanese)

\section{CONTACT}

\section{A. MORIYOSHI (age 59)}

Affiliation: Professor (Dr.)

Department of Civil Engineering

Faculty of Engineering

Hokkaido University

Sapporo, Japan

Field: Highway Engineering, Mechanical Behavior of Bitumen and Bituminous Mixture, Evaluation of Bituminous Pavement, Application of New Bituminous Materials

Education: Graduated (1972) from Ph.D. course in Civil Engineering, Hokkaido University

E-mail: moriyosi@eng.hokudai.ac.jp

Tel/Fax: +81-11-706-6204 